\title{
La unidad de la Iglesia Su desarrollo en la eclesiología-biográfica de John Henry Newman (II)
}

\author{
Ricardo Miguel Mauti \\ Facultad de Teología - Universidad Católica Argentina \\ ricardomauti@uca.edu.ar \\ Recibido 06.05.2020/10.07.2020 \\ DOI: https://doi.org/10.46553/teo.58.135.2021.p141-162
}

\section{RESUMEN}

El artículo, segunda parte que continúa lo publicado en Teología 133, de diciembre 2020, pp. 77-94, cierra la presentación de la tesis doctoral defendida por el autor en diciembre de 2016, en la Facultad de Teología Santa María de los Buenos Aires de la Pontificia Universidad Católica Argentina, bajo la dirección de Fray Dr. Jorge A. Scampini op. El título: «La unidad de la Iglesia. Su desarrollo en la eclesiología-biográfica de John Henry Newman», es justificado desde dos tópicos unidad en desarrollo y eclesiología-biográfica. La tesis intenta, por una parte, superar una concepción estática de la propiedad de unidad en la Iglesia, que ha dominado en la eclesiología católica desde la contrarreforma y que ha imposibilitado el diálogo entre las iglesias; por otra parte, busca descubrir el desarrollo de la idea de unidad en el entramado existencial de la vida de Newman; mostrando las correspondencias y paradojas que se establecen en los dos períodos confesionales en los que vivió el autor (anglicano-católico).

Palabras clave: Newman; Iglesia; Unidad; Desarrollo; Eclesiología-biográfica.

The Church's unity. Its development within the biographical-ecclesiology by John Henry Newman

\section{ABSTRACT}

The article, second part that continues what was published in Theology 133, of December 2020, pp. 77-94, closes the presentation of the doctoral thesis which has been defended by its writer in December 2016, at the Faculty of Theology Santa María de 
los Buenos Aires belonging to the Pontifical Catholic University of Argentina, which is under Friar Dr. Jorge A. Scampini op.'s direction. Its title is «The Church's unity. Its development within the biographical-ecclesiology by John Henry Newman», is being justified by two topics: developing unity and biographical ecclesiology. The current thesis aims, on the one hand, to outstrip a static concept of the Church unity which has been dominating in the Catholic ecclesiology since the catholic Counter-Reformation and has also prevented the communication and dialogue between the different churches. On the other hand, it also aims to discover the development of the idea of unity within the existential framework of Newman's life, thus showing the similarities and paradoxes that have been established in the two confessional periods during which the author (an Anglican-Catholic) has lived.

Key words: New man; Church; unity; Development; Biographical Ecclesiology.

\section{Articulación de los ejes temáticos en los principales núcleos teológicos}

Uno de los rasgos distintivos que se desprende de la eclesiología de Newman, es haber aportado una visión dinámica e integradora a la noción de unidad. Tiene esto que ver, por un lado, con el lugar que ocupa su biografía como instancia hermenéutica; podemos decir con Bernard Lonergan, que el descubrimiento progresivo de las doctrinas como el modo de su asimilación, lleva la impronta de aquel que las asimila. ${ }^{1}$ No es extraño verificar que esta impronta y asimilación (su dimensión subjetiva/biográfica) esté muchas veces marcada con avances y retrocesos en una búsqueda siempre superadora de cuestiones, que desconcierta sin embargo a sus lectores más cautos. Por otra parte, es necesario señalar, para no caer en una visión reductiva de su proyecto eclesiológico, que el polo subjetivo a partir del cual Newman piensa la Iglesia, se articula simultáneamente con el polo objetivo, que es el de una verdad dada que lo antecede y que inserta el complejo de su reflexión en el marco más amplio y abarcativo de la revelación como verdad histórica. A partir de aquí puede comprenderse de qué modo los tres principios enunciados: sacramental-dogmático, escatológico-histórico y jurídico-institucional, configuran las opciones que Newman hace en el abanico de temas eclesiológicos en

1 Cf. Bernard Lonergan, Método en Teología (Salamanca: Sígueme, 2006), 292. 
los que ve implicada la unidad de la Iglesia. Entre estos temas enumero tres, que considero importantes y que aquí sintetizo pero que en la tesis son desarrollados con cierta amplitud:

\subsection{Relación entre Sagrada Escritura y Tradición}

Durante los años de maduración del Movimiento Tractariano, la cuestión sobre la relación entre Escritura y Tradición, tuvo un importante desarrollo en las Conferencias sobre la función profética de la Iglesia (1837). En esta obra, Newman encuadra el análisis ubicando la posición anglicana «entre el error protestante y el error romano» (VM 79). La contraposición confesional se concentra sobre un punto preciso ¿hay una sola fuente de la revelación la Escritura, o existen dos fuentes? Este tema que evidentemente hace pensar en el Concilio Vaticano II que lo abordó como su primer debate doctrinal, aparece aquí esbozado en algunas de sus líneas. Newman insiste en que la revelación está ligada a un acontecimiento histórico realizado de una vez para siempre, cuyo contenido se ha fijado en las Escrituras que debían transmitirse. En este marco de transmisión es donde sitúa la relación entre Escritura y Tradición: «la Iglesia no es el juez del sentido de la Escritura sino su testigo» (VM 283). En este aspecto me he querido detener, mostrando la incidencia eclesiológica de la relación Escritura-Tradición, y la preocupación de Newman por superar un punto de controversia, que enfrentó a la Iglesia anglicana con la Iglesia romana. La Escritura sola no puede atestiguarse a sí misma, pero puesto que está en la Iglesia como Escritura divinamente inspirada, debe atestiguar en la tradición lo que debe ser creído: «ambas en conjunto constituyen una norma combinada; la Escritura se interpreta por la Tradición, la Tradición se verifica por la Escritura, la Tradición da forma a la doctrina, la Escritura le da vida» (VM 288). ${ }^{2}$ Newman ha visto con bastante

2 «Es un error buscar en la Escritura todas y cada una de las distintas proposiciones de la doctrina católica [...] la cuestión no consiste, pues, en si tal o cual proposición de la doctrina católica se encuentra, o no, in terminis dentro de la Escritura, a menos que queramos ser esclavos 
claridad, que la Escritura es siempre recibida y comprendida en la Tradición; ${ }^{3}$ la prioridad cronológica del mensaje evangélico transmitido oralmente representa en la Escritura la máxima concretización de la enseñanza oral. ${ }^{4}$

\subsection{Justificación por la fe: corazón de la Via Media}

La doctrina de la justificación de los pecadores por parte de Dios, es uno de los aspectos centrales de la fe cristiana, y ocupa un puesto singular en la historia de las opiniones religiosas de Newman. Además, es uno de los puntos salientes en el corazón de las disputas entre teólogos católicos y de la Reforma y constituye un argumento obligatorio en el diálogo ecuménico actual. Según Newman la doctrina de la justificación no debe ser puesta en un cuadro aparte puramente teórico; en su vida representa un argumento de repercusión existencial considerado estrechamente ligado a su trayectoria religiosa, que a través de la High Church anglicana lo llevó desde el calvinismo de su juventud a la Iglesia romana. Sin embargo, en 1820 encontramos un Newman jóven de 19 años, convencido de no haber recibido con el bautismo ninguna regeneración espiritual, y consciente de que el cambio interior necesario para entrar en el reino de Dios se ha producido en él por una experiencia de conversión acontecida en 1816: myself and my Creator. Ya en 1825, después de haber leído abundantemente a los racionalistas (Paine sobre el AT, Hüme sobre los milagros, y otros; cf. Apo 31), abandona la doctrina de la justicia extrínseca y de la regeneración separada del bautismo, y comienza en cierto modo un período en el que habla del bautismo como medio de gracia y justificación, al tiempo que se aparta del criterio subjetivo de la conversión propia de la corriente

de la letra. Lo que importa es si se encuentra allí aquella única idea del Misterio, de la cual son exponentes todas esas proposiciones [...] La Escritura tiene que imprimir en nosotros una sola cosa: la idea católica, en ella se incluyen todas», US XV, 225-226.

3 Los términos receive, understant son comunes en $V M$.

4 Cf. Francis McGrath, Universal Revelation (Kent: Burns \& Oats, 1997), 111. 
Evangelical y abraza el criterio objetivo del rito bautismal. De este período hay tres sermones: The Gift of the Spirit; Regenerating Baptism; Infant Baptism; los tres predicados en 1835 con cierta unidad y confluencia de temas. Pero es en el sermón Human Responsability de 1835 (PPS II, 26) ${ }^{6}$ donde Newman formula por vez primera una de las ideas centrales de las Conferencias sobre la justificación: «la gracia de la regeneración bautismal es un don especial que se otorga no gradualmente sino de una vez para siempre...es un estado distinto de cualquier otro, que consiste en la presencia del Espíritu de Cristo en el alma y en el cuerpo». El objeto principal de las Lectures de 1838, es demostrar que la doctrina de la justificación por la sola fe no es irreconciliable, con las ideas tractarianas que hablaban de regeneración bautismal, poniendo de relieve los aspectos sacramentales y atribuyendo un rol esencial a la caridad y a la obediencia en la caridad. ${ }^{7}$ La doctrina de las doce conferencias sobre la justificación, se hallan admirablemente resumidas en un sermón de 1840: Righteousness not of us, but in us (PPS V, 10). ${ }^{8}$ Newman parte de una lectura complexiva de textos paulinos (más de 30 citas) leídas desde los acentos propios de los padres griegos, y alternando con textos litúrgicos tomados del Book of common Prayer, y desarrolla una teología de la gracia, poniendo el acento en la divinización del hombre, llamado a la comunión con Dios y a la participación de su vida en Cristo. Las Conferencias sobre la justificación se caracterizan por un tono áspero y polémico en la confrontación con las ideas de Lutero tal como las entendía Newman en su momento. Puede decirse que las ideas del Reformador alemán constituyen el punto de arranque de su construcción positiva. No he creído necesario examinar si la imagen que Newman tiene de Lutero corresponde fielmente a aquella que nos ofrecen las fuentes y los estudios de los que disponemos actualmente, seguramente no, y no es tema que aporte

5 Los sermones: «The Gift of the Spirit», PPS III, 18; «Infant Baptism», PPS VII, 16.

6 El sermón «Human responsability», PPS II, 26.

7 Es el tema de la II Conferencia: «El amor considerado como la causa formal de la justificación».

8 El sermón: «Righteouness not of us, but in us», PPSV, 10. 
al argumento en cuestión. Sin embargo, si bien la información que Newman disponía era tal vez imprecisa sobre algunas afirmaciones discutibles, el conjunto en general parece responder a la esencia de la doctrina luterana tal como era interpretada por la teología anglicana de los siglos XVII y XVIII, y esa sea tal vez la razón de la recepción benévola que ha tenido esta obra en la teología posterior. ${ }^{9}$

\subsection{Una eclesiología apologética en búsqueda de argumentos para el diálogo}

Hay que reconocer que el proceso que siguió al paso de la Iglesia Católica, tuvo para Newman el significado de un paciente descubrimiento del catolicismo, que le exigió en repetidas oportunidades, tener que dar razones de su nueva condición..$^{10}$ La conversión personal y el desafío de tener que demostrar ante un público plural los motivos de credibilidad de su fe católica, fueron el estímulo para incursionar de manera creativa en otros géneros literarios donde supo volcar su reflexión teológica (v gr. novela y la conferencia satírica). ${ }^{11}$ En esta asimilación progresiva del catolicismo, pueden constatarse dos vertientes que de suyo parecen inconciliables: apologética y ecuménica. En un pasaje de la Apología (1864), después de releer el itinerario de sus ideas y opciones religiosas, Newman se anima a mantener unidas afirmaciones aparentemente contradic-

9 Puede verse en Bernard Sesboüé, Salvati per Gratia. II dibattito sulla giustificazione dalla riforma ai nostri giorni (Bologna: EDB, 2012), 149, 161, 173 passim. El autor muestra la influencia de Newman en teólogos como Hans Küng, La giustificazione. La dottrina di K. Barth. Riflessione cattolica (Brescia: Queriniana, 1969).

10 «Usted me pregunta si he encontrado en la Iglesia católica lo que yo esperaba y deseaba. Depende de lo que quiera decir esperaba y deseaba. Porque yo no esperaba ni deseaba ninguna paz y satisfacción, como usted lo expresa, ni ninguna iluminación o éxito. No esperaba ni deseaba otra cosa sino la voluntad de Dios, y tenía miedo de no cumplirla. Yo no abandoné la Iglesia anglicana a causa de ningún escándalo, como usted piensa. Usted ha equivocado la persona. Mi razón fue la siguiente: sabía que era necesario, si yo quería participar de la gracia de Cristo, buscarla ahí donde Él la había depositado y he creído que tal gracia podía encontrarse solamente en la comunión romana y no en la anglicana, por tanto, me hice católico. Sobre la otra pregunta, si desde que me hice católico he sido bien o mal tratado, de altos personajes o de amigos íntimos, esto no toca para nada la cuestión de la verdad o el error de la Iglesia o el cisma», Carta a Edward Husband (July $17^{\text {th }}, 1870$ ), LDXXV, 160.

11 Para este argumento: Ian Ker, «John Henry Newman's discovery of Catholicism», op. cit., 22 . 
torias, dice: «Yo supongo que la causa principal de este modo de ver radica en el contraste que me ofrecía la Iglesia católica. En ella reconocí inmediatamente una realidad que era algo completamente nuevo para mí. Me di cuenta de que no me estaba fabricando una Iglesia para mí mismo a base de esfuerzo mental [...] Y más adelante agrega: La Iglesia de Inglaterra ha sido para mí el instrumento de la Providencia para hacerme grandes beneficios...de no haber ido a Oxford, tal vez no hubiera oído nunca una sola palabra sobre la Iglesia visible, sobre la tradición y otras doctrinas católicas». El contraste que le ofrece la realidad vivida, es un punto de observación que le permite leer reflexivamente la historia de la Iglesia (anglicana y católica), dando cuenta en primer lugar de una coincidentia oppositorum que puede descubrirse en el cristianismo, y en la historicidad de la Iglesia y que aplica de continuo en su método teológico. En general puede decirse que allí donde una mente estrecha (norrow minds) solo vería oposición, Newman busca integrar realidades en apariencia opuestas. ${ }^{12}$

Aunque en contextos diversos y con motivaciones y formas que superan el sermón y el ensayo hasta ahora empleados, este método apologético-ecuménico, se expresa en tres temas principales:

1) la posición de los católicos en Inglaterra: en donde intenta desnudar las intenciones profundas del prejuicio confesional, como barrera para el entendimiento común y la convivencia pacífica. En las Lectures on the present position of catholics in England, ${ }^{13}$ frente a la necesidad de tener que despejar prejuicios instalados en la cultura inglesa a través de la historia y la literatura gestada a lo largo de tres siglos, busca descender al núcleo de la crítica lanzada hacia los católicos. Para ello, recurre a motivos de credibilidad extraídos en gran parte de acontecimientos históricos que a su juicio ayudan a

12 Newman tiene una página antológica en la descripción de lo que denomina narrow minds y que considera uno de los grandes obstáculos para la realización de la unidad en todos los niveles; cf. Wisdom as contrasted with faith and with bigotry, "La sabiduría contrapuesta a la fe y al fanatismo», US XIV, 208.

13 John Henry Newman, Lectures on the Present Position of Catholics in England (Leominster: Gracewing, 2000). 
distinguir ambas posturas eclesiales. En el planteo metodológico que esbozará en la primera conferencia, enuncia un criterio clave: «En todas las cosas, hay dos lados: el lado católico del argumento y el lado protestante [...] si bien la verdad es una sola, los argumentos son muchos y en toda disputa siempre hay dos lados que deben intentar encontrarse» (Prepos 5; ECH II, 5). En defensa de una posición que no niega la evidencia de los hechos, dice Newman, «no todo lo que se dice de nosotros los católicos está privado de fundamento», busca asumir la raíz de la crítica elevando el punto de mira y transformando en reflexión teológica el argumento adversario. Para el ejercicio de esta peculiar apologética (que no se limita a la defensa desde argumentos definitivos) Newman se deja llevar por el principio de que: «lo que es bueno para unos puede ser mortal para otros», ${ }_{r}^{14}$ de allí que para fijar la posición católica, proceda siempre, iluminando la historia desde hechos comunes a ambas confesiones, y buscando dejar abierto el ángulo de la discusión.

2) las dificultades de los anglicanos entorno a la mariología: el ambiente anticatólico en que se gestó gran parte de la teología del autor, puede hacer pensar que la doctrina mariana adolezca sustancialmente desde su época anglicana. Pero es necesario considerar que las manifestaciones excesivas de devoción hacia María constituyeron en su momento su 'gran cruz respecto del catolicismo'. Newman creía sobradamente que una especial forma devocional había recibido la más plena aprobación por parte de Roma y de la que hacía un amplio uso, como bandera de identidad confesional. Durante el período tractariano, al menos desde 1839, considera que la devoción católica a los santos y en especial a la Virgen, constituye la esencia misma de la corrupción y del error teológico de Roma. El lugar que María ocupa en el credo católico y en las devociones, no constituye un problema solo para Newman, sino que está en el centro de las sospechas y temores de los anglicanos, que pensaban que aquellas formas de devoción que invocaban a María como "me- 
diadora junto al Redentor', dejaban en la sombra el honor debido a Cristo, interfiriendo en su papel de único mediador. La devoción a María del Newman anglicano, se basa en el dato bíblico y en las formulaciones que se desprendían del dogma cristológico, como lo prueba ampliamente su homilética. ${ }^{15}$ El estudio de los Padres le permitió comprender los desarrollos que se habían dado en el curso de la Tradición, como también captar con mayor amplitud las razones de quienes defendían determinadas prácticas devocionales. Sin embargo, un tono de reserva y moderación acompaña en este período su reflexión, tanto para no turbar a sus amigos anglicanos, como por temor a verse involucrado en doctrinas y prácticas que aún consideraba erróneas.

En el período católico se registra un avance en la comprensión del tema; una vez más una ocasión externa sirve de oportunidad para profundizar en las propias ideas. El teólogo anglo-católico E. Pusey, con la esperanza de restablecer la unidad visible de las iglesias separadas, acababa de escribir su Eirenicon, bajo el título «La Iglesia de Inglaterra, porción de la única Iglesia de Cristo», allí ataca el culto a María, considerándolo obstáculo principal del sistema romano. La denuncia, iba formalmente dirigida a lo que se consideraba una devoción desviada, en contraste con lo que habían sido los desarrollos normales y las manifestaciones legítimas de la piedad cristiana. Pusey había tenido el mérito de formular en un texto erudito y exhaustivo las principales objeciones anglicanas hacia lo que consideraba corrupciones católicas, provocando de este modo la reacción de Newman que opinaba que su amigo «disparaba su rama de olivo desde una catapulta». En efecto, pese a las intenciones irénicas de Pusey, muchas de sus afirmaciones, tanto en la forma como en el fondo resultaban punzantes para los católicos. Newman responde con una carta que se convierte en un pequeño tratado de mariología, en donde desarrolla temas como: madre de Dios, segunda Eva, madre de santidad, puntos de la tradición donde ve en 
continuidad a Iglesia de los Padres con las posturas anglicana y católica. Entre estos aspectos, considera que el método con que Pusey presenta la doctrina no termina de ser imparcial, al insistir con desmesura en los puntos de divergencia entre anglicanos y católicos, en lugar de allanarlos mediante una comprensión que pusiera más a la luz la dimensión histórica de algunas afirmaciones. Señala por ejemplo un recurso indiscriminado a opiniones extremistas que no eran representativas de la doctrina católica en temas para los que se proponían como autoridades.

La carta a Pusey es expresión de cómo concibe Newman la piedad mariana, caracterizada por una tensión entre racionalidad teológica y afectividad creyente, en cuanto que pertenece a su esencia no dejar que ninguna de ambas se atrofie, no olvidando en el affectus la sobria medida de la ratio, pero tampoco ahogando con la sobriedad de una fe inteligente al propio corazón, que a menudo ve más que la pura razón. Newman un inglés hasta la médula, cuya espiritualidad parece siempre cuidarse de manifestaciones emocionales, reconocería a la distancia con admiración la piedad mariana de nuestro pueblo, que tantas veces en su desborde expresa la vitalidad de una fe enraizada en el amor; dice: «La religión obra en los sentimientos; cuando éstos están excitados, ¿quién puede detenerlos en su crecimiento y en su salvaje carrera? [...] De todas las pasiones, el amor es la pasión más difícil de dominar; más aún, para ser franco, yo tendré muy poco un amor que está siempre preocupado por las conveniencias, que no exagera nunca y que, en cualquier circunstancia, sabe controlarse tan bien que no permite excepciones a las normas protocolares y de pragmática de un perfecto buen gusto» (Diff II, 84-85).

3) la cuestión de la infalibilidad pontificia: el tema de la infalibilidad papal tiene al igual que en la historia de la eclesiología un largo camino en los intereses de Newman. Las ideas germinales deben buscarse en la VM:

«La doctrina romana, con su profesión de infalibilidad, además de desvirtuar el carácter misterioso y sagrado del Evangelio, rebaja el nivel y la calidad de la obediencia que debemos al mismo; y esto de varias maneras. 
Cuando todos los elementos de la religión se han sistematizado, corremos el riesgo de que algo terreno, en lugar de nuestro Creador se convierta en el objeto principal de nuestra contemplación. Ahora bien, Roma clasifica nuestros deberes y sus recompensas, lo que hay que creer, las cosas que hay que hacer, los modos de agradar a Dios, los castigos y los remedios del pecado, con tanta exactitud que un individuo sabe exactamente-por decirlo así- dónde se encuentra en su camino hacia el cielo, hasta dónde ha llegado y cuánto le queda por recorrer; de modo que sus obligaciones se convierten en materia de cálculo». ${ }^{16}$

La identificación de la Iglesia con el papado es un proceso lento, gestado en una corriente de pensamiento que se alimentó de múltiples fuentes, como lo han demostrado historiadores como Schatz, Aubert y O’Malley y teólogos como Congar, Tillard y Pottmeyer. La obra del monje camaldulense Mauro Cappelari Trionfo della S. Sede e della Chiesa contro gli assalti dei novatori combattuti e respinti colle loro stesse armi, publicada en 1799, tendrá su autorecepción y difusión amplificada en 1831 cuando su autor sea elegido para la sede de Pedro con el nombre de Gregorio XVI. Esta obra constituye bajo muchos aspectos el anticipo del ultramontanismo, que entre los autores ingleses tuvo en E. Manning su mayor exponente. No me detendré en el análisis de la evolución del pensamiento de Manning, antiguo arcediano de Chichester luego como católico, $2^{\circ}$ arzobispo de Westminster, pero es evidente que su posición, con la que Newman rivaliza, resulta vital para comprender la marcha que llevó a la definición de 1870. Paradójicamente y en contrapartida con el proceso que se registra en Newman, la posición de Manning sobre la unidad y la infalibilidad de la Iglesia, parece más clara en la etapa anglicana, al integrar la cuestión de la autoridad en el marco más amplio de la sacramentalidad de la Iglesia. ${ }^{17}$ Pero una vez católico, Manning ingresa de manera comprometida en la "corriente infalibilista" convirtiéndose en el abanderado del grupo ultramontano. Una instancia decisiva en el rumbo que toma el "espíritu de la definición' es la carta pastoral The Centenary of Saint Peter and the

17 Así en: The Unity of the Church (1842); The Temporal Mission of the Holy Ghost (1865). 
general Council de $1867,{ }^{18}$ donde se orienta con acentos significativos hacia una exaltación del primado: el papa es infalible apart from the bishops, es decir separado de los obispos, lo cual significa llanamente: «sea lo que fuere lo que piensen los obispos». En síntesis, la trascendencia de la posición de Manning confluye en el desarrollo que asume su teología del papado, particularmente del poder temporal que curiosamente entiende como respuesta a la soberbia de los intelectuales tanto historiadores como teólogos.

Por su parte Newman que participa distante pero reflexivamente activo entorno a los debates del Vaticano I, sintetiza así su postura: «¿Cuándo una definición de fide ha sido un lujo de la devoción y no una necesidad seria y dolorosa?» Esta pregunta encierra la perplejidad que le provoca la posibilidad de la elevación del primado papal de jurisdicción e infalibilidad al rango de dogma, a la vez que el temor ante la pérdida de sentido que podía llegar a tomar un concilio en el futuro. Newman, que había llegado al catolicismo por el testimonio de los Padres que vivieron en época de la Iglesia indivisa, sabe que en la antigüedad las definiciones dogmáticas cumplieron su función en situaciones extraordinarias, como la amenaza de una herejía que podía poner en peligro la verdad del depositum fidei y la consecuente unidad de la Iglesia. Pero las circunstancias históricas del Vaticano I eran totalmente diversas, no había verdades de fe amenazadas y el primado romano había recuperado su prestigio. Sin embargo, el clima ultramontano, crecido a la sombra del pontificado de Pío IX, propagó rápidamente la idea de un papado fuerte e incontestable en su centralidad romana, concebido como bastión a la vez que antídoto frente a los ataques del mundo moderno. Por primera vez, el acto de definición del magisterio se trasladaba de las doctrinas de fe hacia la persona y el ejercicio del ministerio que debía custodiarlas. Newman se lamenta que la agitación ultramontana haya colaborado para revivir escándalos pasados del papado, además de socavar los esfuerzos de los high

$18 \mathrm{Cf}$. James Pereiro, El cardenal Manning. Una biografía intelectual (Madrid: Cristiandad, 2007), 290. 
anglicans de fermentar la masa protestante. Pero, mientras las discusiones sobre la infalibilidad siguen su curso con amplia resonancia antes de la definición, y los obispos debaten en concilio divididos en tres grupos al parecer bien identificados (infalibilistas extremos, pocos numerosos, pero cercanos a Pío IX; la minoría contraria a la definición; y una mayoría favorable pero sensible a la preocupación de la minoría); Newman se plantea la pregunta: «¿por qué si creo en la infalibilidad papal no deseo que sea definida?» y responde: «porque no puede ser definida si no levanta más cuestiones que las que resuelve». En síntesis, Newman manifestó reservas hacia la definición por dos razones que podemos denominar de orden dogmático y pastoral-ecuménico: 1) creía que no era necesaria, si con ello se entendía completar en algo el depositum fidei, pues tal como mostraba la historia era peligroso ir más allá de las normas de la tradición en tales cuestiones; 2) porque era una ocasión para perturbar las almas de las personas haciendo más difícil la defensa del catolicismo. Con todo, aún después de la definición, insistirá en la necesidad de considerar el «nuevo dogma» no aisladamente sino en su nexo íntimo con la verdad de la Iglesia, y señalando un aspecto más que remite a la comprensión sintética de las notas de los desarrollos doctrinales: «Si miras a la historia, verás que los papas completan continuamente los actos de sus predecesores, y lo mismo vale para los concilios, no dudo que un futuro papa, o un futuro concilio, explicarán y guardarán lo que ha sucedido en este último concilio, para esclarecer todo aquello que ahora es un problema».

\section{Esbozo del carácter católico de la unidad}

He intentado hacer una presentación diacrónica del desarrollo de las verdades de fe que integran el descubrimiento de la unidad en el marco de una vida, y que con Jaki Stanley denomino «eclesiología 
existencial». ${ }^{19}$ Los temas que jalonan esta progresiva asimilación bien pueden representar un stromata, un tapiz (tapestry) según unas de las acepciones del vocablo dado a la obra de Clemente de Alejandría, de la que Newman hace particular uso. La eclesiología de Newman puede ser comparada a un tapiz mirado desde el reverso, donde una multiplicidad de temas como hilos conductores se entrecruzan, dando la impresión de una desconexión con el conjunto de la imagen que aflora en el anverso. En esta presentación he mencionado algunos de estos temas y dejado otros por razones de tiempo; no he hablado de la dimensión pneumatológica, de su eclesiológica, tampoco de las cuestiones relativas a la Eucaristía ligadas a su fe anglicana y católica, ni de la idea del laico y del valor del sensus fidei. El itinerario de sus ideas como hemos podido observar no ha sido lineal; hay avances y retrocesos que dejan la impresión de no alcanzar un orden y claridad al momento de una asimilación del conjunto. Desde esta perspectiva quiero situarme al plantear desde una visión sincrónica algunos aspectos que permitan una mejor captación de la intención que subyace en el autor en su búsqueda de la unidad en la catolicidad.

\subsection{La unidad de la Iglesia como paradoja en un proceso vital}

Las imágenes bíblicas de edificación y crecimiento en la eclesiología neotestamentaria dan idea de un progreso personal y comunitario de la Iglesia. La salvación se realiza en cada miembro y en la comunidad, de una vez para siempre, pero a la vez de modo procesual y continuo. Es Dios quien pone el fundamento en la historia revelando la unidad de su misterio, desplegando en el tiempo todas las potencialidades de su obra que deben aún descubrirse y que en virtud de su naturaleza no se deja reducir a mera uniformidad. La unidad de la Iglesia expresada en la communio, tiene la forma de la cruz en cuanto es fidelidad a lo que viene de lo alto como

19 Cf. Jaki Stanley, Newman to Converts. An Existential Ecclesiology (Michigan: Real View Books, 2001), 487. 
procedente de Dios, pero con capacidad creativa, por lo cual el don se hace contemporáneo y significativo en su mensaje, con poder de asimilar lo diverso y de expresar mejor aquella plenitud que debe ser dicha y vivida de muchos modos. Es por ello que la unidad no exige para sí lo estático como única forma eficaz de asegurar la fidelidad a los vínculos vitales, expresados en el dogma y la disciplina, sino que reclama lo dinámico que a su vez supone la recepción permanente de la verdad interpretada en el interior de la tradición viva. Un ejemplo de esto es la creación del oratorio inglés por parte de Newman, un momento significativo de su biografía que he 1lamado 'experiencia eclesial de unidad'. Allí planteo las cuestiones de por qué elige el oratorio y no otra forma eclesial para vivir su condición católica, la idea que tiene del oratorio, como continuidad con el 'espíritu filipino' pero extrapolado del molde italiano y encarnado y reinterpretado en molde inglés. E1 oratorio de Birmimgham es un microcosmos de su comprensión de la Iglesia.

\subsection{Superación de la idea estática de unidad}

En segundo lugar vemos una concreción de este aspecto en el modo como el autor, para superar una idea estática de unidad que predominó en la teología de la contrarreforma y que influyó en su inicial formación católica, intenta recapitular su eclesiología anglicana desde una relectura a partir del triple oficio (profético, sacerdotal, real) concebido desde el entero cuerpo eclesial, y no solo desde el ministerio jerárquico, con lo cual busca equilibrar desniveles que históricamente afectaron una realización más católica de la unidad, que se debate siempre entre las polarizaciones del laicismo y el clericalismo.

\subsection{Lo 'católico' de la unidad}

En tercer lugar, considero lo «católico» de la unidad. En la visión que Newman alcanza de la unidad eclesial, se encuentra siempre 
viva la convicción de que la verdadera Iglesia no solo es visible en la conjunción e interrelación de sus propiedades, sino que ellas son una garantía que Dios ha previsto para acreditarla en la historia. En el caso de la unidad aparece ligada a la catolicidad bajo dos aspectos: por la unión que Cristo establece con su Cuerpo, como por el sentido de una visión totalizante y universal que determina su comprensión de la Iglesia. Según este aspecto la esencia del catolicismo, para decirlo con Karl Adam que en esto sigue a Newman, consiste en «permanecer en un justo medio». ${ }^{20}$ Lo católico se constituye en una cualidad teológico-espiritual para Newman, por la que capta el todo en la parte, aunque no siempre pueda verificar el modo como ello se realiza. En este proceso de asimilación de la unidad he destacado cuatro elementos, que no desarrollaré aquí, en los que cabe identificar su eclesiología-biográfica: el carácter propiamente teológico de la unidad, el papel de la tradición como lugar de inserción, la unidad como desarrollo en la tradición y la conversión como principio de su dinamismo.

Newman vivió esta experiencia como búsqueda y hallazgo guiado por la certeza de no «haber jamás pecado contra la luz», y tuvo la capacidad para objetivar sus planteos existenciales más profundos registrados al hilo de su propia biografía. La experiencia religiosa de Newman fue más una evolución que una mutación. Su descubrimiento del catolicismo significó más un crecimiento que una renuncia a lo anterior, un acto de añadir y no de eliminar. El catolicismo lo completó; pudiendo afirmarse que fue un hombre de continuidades en el cambio. Tenía en este sentido una concepción unitaria de su convicción religiosa. 


\section{Conclusiones generales}

Nuestra investigación ha buscado profundizar lo que constituye el descubrimiento de la Iglesia en una unidad en crecimiento; contribución que desde una mirada retrospectiva resulta amplia en sus dominios. El amplio espectro de vivencias pensadas y de ideas vividas, hacen de la eclesiología de Newman una realidad dialéctica plasmada, como ha notado Ian Ker en la constante relación que se establece entre lo real y lo nocional. ${ }^{21}$ Se evidencia en Newman una constante interacción entre fe, pensamiento y vida, reflejada en un proceso que constituye el descubrimiento y asimilación de la unidad de la Iglesia. La visión que ofrece la meta alcanzada es amplia, aunque aquí optemos por señalar tres constataciones que nos sitúan ante: 1) un autor que posee un estilo de pensar la fe y que reaviva la cuestión siempre candente de quién es un teólogo; 2) un modelo de eclesiología que se constituye desde el contraste por un camino diverso al sistema y que plantea un nuevo modo de comprender la unidad, y 3) un pensamiento con vigor perenne y capacidad proyectiva.

1) El estilo del teólogo: ¿Qué estilo de teólogo emerge de esta eclesiología-biográfica? ${ }^{22}$ La posibilidad de encuadrar la realización teológica dentro de determinados parámetros conceptuales, es una cuestión que preocupó a Newman como pensador: «teólogo es aquel que conoce a fondo la teología, alguien que puede decir cuántas opiniones hay sobre cada cuestión, qué autores las han tratado, y cuál es la mejor de ellas; que sabe discernir atentamente entre una proposición y otra, que puede trazar la historia de las doctrinas en el curso de los siglos y aplicar los principios de los tiempos precedentes a las condiciones del presente. Esto debe ser un teólogo, esto y cientos de cosas más; y esto yo no lo soy ni lo

21 Cf. Ian Ker, Newman on Vatican // (Oxford: Oxford University Press, 2014), 81.

22 «El estilo define una propiedad o una cualidad, o sea la coherencia interna de una obra singular o la maestría que ella revela en su autor»; Cf. Christoph Theobald, / Cristianesimo come stile. Un modo di fare teologia nella postmodernità, 1 (Bologna: EDB, Bologna, 2010), 12. 
seré jamás». ${ }^{23}$ Es evidente que Newman conocía la premisa clásica: «teología son aquellas verdades que conocemos de Dios y que son integradas en un sistema», aunque no parece que en la práctica haya intentado y menos aún logrado realizarla con cierto éxito. Una razón de esta dificultad tiene que ver con algo de su personalidad y que Nicholas Lash intentó individualizar llamando la atención sobre «la intimidad entre discurso y quien habla, y entre el texto y quien piensa, lo cual constituye el signo distintivo de su genio». ${ }^{24}$ Es necesario por consiguiente plantear desde qué presupuestos se hace teología, para alcanzar una determinada idea del estilo del teólogo y del alcance que debe esperarse de su producción. ${ }^{25}$ En el caso de Newman: elaborar la Via media para dar entidad a la Iglesia de Inglaterra, plantear el problema del "desarrollo doctrinal" buscando semejanzas en cuadros históricos con la Iglesia antigua, reivindicar la consulta a los laicos en materia doctrinal, justificar la diversidad de formas del culto mariano y criticar la inoportunidad de la definición de la infalibilidad papal, significaba mucho más que temas destinados a integrar un sistema de pensamiento. ${ }^{26}$ Por el contrario, eran cuestiones vitales ligadas a su búsqueda de unidad en la fe y al sentido de pertenencia a un cuerpo eclesial del que se sentía responsable, tanto desde el pensamiento como desde la acción influyente de su palabra. En este sentido no se le podrá reprochar al autor que no esté unido al objeto de su estudio, aunque sus intereses excedan cualquier demanda científica y académica. Tal vez las herramientas de reflexión y exposición de que dispuso no hayan sido las comunes a una tradición teológica crecida al abrigo de la filosofía, y que ha alcanzado parámetros únicos en el esfuerzo del orden y seriedad del concepto. Este límite es insalvable en su teología. Sin embargo, teólogo es también quien sintetiza en sí las conquistas y contradiccio-

23 LD XXIV, $212-213$.

24 Nicholas Lash, «Tides and twilight: Newman since Vatican Il», en A. G. Hill (dir.), Newman after a Hundred Years, (Oxford: Clarendon Press, 1990), 451-452.

25 Terrence Merrigan, «Newman on the practice of theology», Louvain Studies 14 (1989) 260; «Newman the theologian», Louvain Studies 15 (1990) 103-118.

26 Cf. Roderick Strange, Newman. A mind alive (London: Darton \& Todd, 2009), 12. 
nes que la inteligencia del misterio inevitablemente lleva consigo, y es capaz de romper el techo de su época movilizando la reflexión en otras direcciones. En este sentido ha señalado Erich Przywara, que la unidad entre temor y amor, entre el Dios exterior e interior, donde Agustín se supera a sí mismo, tiene su plena resurrección en la Edad Moderna en el pensamiento de Newman. ${ }^{27}$

2) El modelo de Iglesia como unidad en desarrollo: ¿Qué modelo de eclesiología, se desprende del estilo del teólogo? El carácter poliédrico de un pensamiento se puede reconocer en la originalidad unida a la versatilidad de un genio, esto hace de la eclesiología de Newman una realidad difícilmente encasillable en esquemas culturales y teológicos preconstituidos. Si en líneas generales se pregunta, desde dónde piensa la Iglesia, la respuesta es sencilla: la Escritura, los Padres, y los teólogos anglicanos del siglo XVII (Hooker con su concepción jurídica y Butler con su «principio sacramental»); sin embargo, en un nivel subordinado, aunque no inferior se ubica su propia biografía como lugar de investigación, interpretación y dialéctica de los datos. El teólogo que aquí ejercita el método se apoya no sólo en su experiencia religiosa privada, sino que procura integrarla con la fe de la tradición cristiana tal como se encuentra representada en la reflexión que otros creyentes han gestado. ${ }^{28} \mathrm{Si}$ se recurre a categorías del Papa Francisco con las que intenta captar la complejidad y riqueza que ofrecen las realidades sociales, es posible relacionar ambos pensamientos, y mostrar que el modelo que se desprende de la eclesiología newmaniana puede expresarse en la figura del poliedro. Un cuerpo tridimensional con múltiples superficies y ángulos, ofrece una variedad de captaciones que no pueden ser agotadas en una mirada unidireccional. La Iglesia en su estructura sacramental refracta como a través de un prisma lo sublime del misterio, como dice Newman: «nunca se deja reducir

27 Erich Przywara, Augustinus, Die Gestalt als Gefüge (Leipizig: 1934), 67.

28 En esta línea hay que ubicar las numerosas semblanzas teológicas de Padres y testigos de la Fe (ej. Pablo, Ignacio, Atanasio, Antonio, Ambrosio, Agustín, Crisóstomo, Savonarola, Felipe Neri, Palmer, Keble, Lamennais, Davison y otros). 
a normas humanas ni permite que le impongan coherencia consigo mismo en sus múltiples aspectos». La imagen resulta apropiada si se acepta que una eclesiología no siempre implica un sistema equilibrado y equidistante de cuestiones tratadas en el mismo nivel de rigor. La reflexión newmaniana sobre la Iglesia, sea por la frecuentación de los Padres como por su particular sentir filosófico, está siempre vuelta a lo concreto, a lo «real», y encuentra consistencia teorética en la revelación cumplida en Jesucristo y en la experiencia humana, aunque su traducción a un cuerpo de doctrina no supere la forma del «ensayo», el «esbozo» o la «idea». En tal sentido, el aporte al legado eclesiológico debe buscarse más en lo que insinúa que en aquello que explicita. Ya hemos dicho del lugar que ocupa la visión pneumatológica en su concepción de la unidad, pues la creación de la unidad pertenece a la naturaleza del Espíritu Santo. Pero es necesario señalar con fundamento en el sentido bíblico que, «espíritu» (ruaj) es el aire en movimiento, y por tanto es impensable sin algún dinamismo (Gn 1, 2; Hch 2, 2). Esta realidad subyace en la idea newmaniana de unidad comprendida bajo la virtud de desarrollo, y permite una asimilación constante de la verdad en la diversidad de elementos, formas y experiencias eclesiales. La idea de Newman de que la vida crece gracias a la polaridad y a las tendencias opuestas, que se equilibran mutuamente, implica, evidentemente, que no todas las partes y funciones tienen la misma importancia ni influencia a la hora de determinar la trayectoria general del pensamiento dentro de la Iglesia.

3) El carácter profético: el Concilio Vaticano II prestó particular atención a la Comunión anglicana al señalar la subsistencia que perdura en ella de estructuras católicas (UR 13). La Iglesia anglicana, como hemos visto, se concibe tradicionalmente como la via media entre el catolicismo y la Reforma. En el seno de la tradición anglicana, es donde Newman comienza a trazar su itinerario teológico-espiritual que lo guiará a la plenitud católica. A lo largo de la investigación, hemos registrado una variedad de intuiciones de alcance profético que lo acredita como un antecesor del movimiento ecuménico. Los temas y circunstancias que le dieron origen, han 
quedado enmarcados en la presentación y análisis de sus obras; finalmente, un rápido enunciado de los mismos, nos permite recordar la actualidad de su aporte. En efecto, la justificación por la fe, la relación Escritura-tradición, el lugar y las formas del culto mariano, la posición del laico en la Iglesia, y la cuestión del ministerio petrino, son temas en los que se reconoce actualmente el diálogo de las iglesias. Newman descubre la unidad en la plenitud de todos estos dones con los que Dios ha dotado a su Iglesia: «una plenitud de satisfacción, en su credo, su teología, sus ritos, sus sacramentos, su disciplina [...] Este es el verdadero secreto de la fuerza de la Iglesia, el principio de su indefectibilidad y el vínculo que asegura su unidad indisoluble». El legado eclesiológico que Newman ha dejado a la Iglesia, es testimonio de su búsqueda sincera y fatigosa de la verdad. En su vida como en su obra, la unidad de la Iglesia parece desplegar un haz luminoso sobre el horizonte de la historia, que se acredita en la santidad que ella busca tal como queda expresado en el epitafio de su tumba: Ex umbris et imaginibus in veritatem (Desde las sombras y las imágenes hacia la verdad). ${ }^{29}$

\section{Bibliografía}

Adam, Karl. La esencia del catolicismo. Buenos Aires: Santa Catalina, 1940.

Honoré, Jean. La Pensée christologique de Newman. Paris: Desclée de Brouwer, 1996.

Ker, Ian. Newman on Vatican II. Oxford: Oxford University Press, 2014.

Lonergan, Bernard. Método en Teología. Salamanca: Sígueme, 2006. McGrath, Francis. Universal Revelation. Kent: Burns \& Oats, 1997.

Merrigan, Terrence. "Newman on the practice of theology», Louvain Studies 14 (1989) 260-284.

29 Cf. E. Ender, «Ex umbris et imaginibus in veritatem», en M. K. Strolz - M. Binder (eds.), John Henry Newman. Lover of Truth (Rome: Urbaniana University Press, 1991), 147. 
—. «Newman the theologian», Louvain Studies 15 (1990) 103-118. Pereiro, James. El cardinal Manning. Una biografía intelectual. Madrid: Cristiandad, 2007.

Stanley, Jaki. Newman to converts. An Existential Ecclesiology. Michigan: Real View Books, 2001.

Strange, Roderick. Newman. A mind Alive. London: Darton \& Todd, 2009. 